ISSN: 2349-2031

(c) 2018, THEIJSSHI

Research Article

\title{
Curriculum, Teaching and Interdisciplinarity
}

\author{
Silvia Morelli ${ }^{1}$, Camila Carlachiani ${ }^{2}$ \\ ${ }^{1}$ Universidad Nacional de Rosario, Argentina / Ministry of Education of Santa Fe, \\ ${ }^{2}$ Universidad Nacional de Rosario, Argentina / Ministry of Education of Santa Fe.
}

\begin{abstract}
This article makes visible the problems around teachers' knowledge regarding teaching and content management. It shows an experience of a proposal of Interdisciplinary Core Content (ICC) created by us for the Ministry of Education of Santa Fe, Argentina. Aided by Shulman's questions and his missing paradigm, we formulate our own questions about the relationship between content and teaching: why is teaching a content-free domain? If it is a problem of curriculum and didactics, what can we do with these dissociated fields of study which need to keep coexisting in the same environment? Addressing the curriculum-didactics in teaching includes the interdisciplinary debates to set up contents. In the curriculum-society relationship, ICC are developed taking the social issues proper of each context about Human Rights, Climate Change, Violence, Energy, Culture, the Space, Nutrition and Health as starting points. As a micro-level curriculum policy, the selection and sequencing of content transforms into a teaching problem. While at the meso-level dialogue, the relationship between curriculum and didactics is strengthened. The event question about what is going on? shows its genealogical nature. This teaching scenario is established based on the didactic triad, conditioned by the institutional context and configured by the special characteristics of each one of the members of the class.
\end{abstract}

\section{Keywords: Curriculum-Didactics; Interdisciplinarity; Content, Teaching.}

\section{Introduction}

Teaching tends to be a subject under dispute between the curriculum and the didactics field. Latter, both of which have different origins and traditions (Anglo American, in the case of curriculum, or German, in the case of didactics) are involved in an epistemological dispute around their boundaries, their objects under examination and the answers each of them offers to the teaching practices. The point is that teaching gets to the current scenarios as an object disputed between two fields, which causes ambiguity towards its definition and generates an empty space where, far from what is intended, it is left to good luck and teacher's will. In order to resolve an epistemological problem between curriculum and didactics and to understand how they approach the teaching issue, we consider both of them to be in a complementary relationship and to share the theoretical and practical concern towards teaching. At the same time, teaching is the conceptual link which articulates curriculum and didactics. This means that when we refer to teaching we will mention both curricular and didactical issues, distinguishing one from the other sometimes and making no distinction some other times.

This text deals with teachers' knowledge regarding teaching and content. We should then ask the inevitable question: Which is the relationship between content and teaching? Is teaching a content-free field? It is important to retrieve, regarding the teaching analysis, the tension that exists between the specific knowledge of a knowledge area and the didactical knowledge. The distortions in this field caused the problem to be identified as dissociated fields in the teaching process, which led to identifying the general didactics, on the one hand, and the specific didactics, on the other hand. More clearly, the problem is shown when we disassociate teaching from the latter (also known as disciplinary didactics or didactics of the disciplines), making the burden of the teaching responsibility to fall on general didactics. So, what should we do with this disassociated relationship which needs to keep coexisting? Here lays one of the biggest problems in teaching and the epistemological commitment to search for meeting points to agree on what we are talking about when referring to it and how teaching involves the didactical issue, which entails the relationship between general didactics and specific didactics.

\section{Teaching, Content and Teacher}

Dealing with teaching takes us to discussing its content and this leads to the didactical tensions retrieving the knowledge from the disciplines or interdisciplines at the moment of their configuration. The relationship between both types of didactics is in itself an interdisciplinary process which accounts for what happens when teaching. This process is incomplete until it is committed in this relationship regarding reflection about the practice (of teaching).

We are interested in recovering what Schulman (1986, p. 8) calls the missing paradigm, when referring to content and teacher's knowledge of teaching as a blind spot. What we are missing is a follow-up regarding what happens in class with the contents taught, regarding the questions asked by the student and the explanations offered, the origin of the teacher's explanations when teaching, or how to question the student when teaching and how to deal with problems of misunderstanding. The challenge in Shulman's explanations about the teacher and the content of a class lies in searching for answers in teaching and not in Psychology, which focuses on how a student learns, ignoring teaching as problem. We propose a twist in learning towards teaching and to investigate 


\section{Camila Carlachiani et al / Curriculum, Teaching and Interdisciplinarity}

how it is taught, what happens to the teacher when teaching, what are the sources of knowledge used by a teacher when teaching, what does a teacher know about the contents taught and how this teacher continues to acquire knowledge on that subject matter, and what is the previous knowledge possessed by a teacher regarding the content development as a didactics issue. These are many questions but there are very few answers which impact in the planning and development of teaching as teachers' professionalism.

In our opinion, teaching is a complex activity, guided by the teacher, which is based on creating situations in which student meets with knowledge. All teaching is an intentional act that seeks specific purposes in the transmission of some knowledge to some students. Shulman (1986, p. 9) notices that there are three categories of content knowledge which the teacher combines when projecting teaching: subject matter content knowledge, pedagogical content knowledge, and curricular knowledge. Content knowledge has to do with the disciplines and the way of organizing them towards the construction of school knowledge. There are many ways of addressing the relationship between teachers and knowledge towards the elaboration of content. We have chosen the manner defined by Schwab: recognizing the substantive and syntactic structures of disciplines. The substantive structure comprises categories, key concepts and theoretical perspectives, while the syntactic structure is formed by the validation criteria and research methodology towards knowledge construction. Pedagogical content knowledge, according to Bolivar (2005, p. 6) is an amalgam of content and didactics. It describes how the teacher understands content and transforms it into something teachable. This category includes the representations, analogies, examples and demonstrations which cut out and specify knowledge of content based on a given group and teaching scenario. This knowledge aids the teacher in finding ways to make content understandable to a group of students in a specific grade or school year and with a certain socio-cultural register. The third category, curricular knowledge, deals with the knowledge of the instructional materials for content learning in particular situations and circumstances. All the variety of materials and possibilities available in order to teach content: texts, software, visual materials, films, demonstrations, research guidelines, etc. Within the same text, Bolivar affirms that knowledge and the teaching materials are related with content and students.

It is important to stress that, although teaching is developed in the classroom and the teacher is the one in charge of its outline and development, it does not belong to the classroom unit exclusively, but also to the institutional one. It is at the school, as a curriculum development unit, where the selection and sequencing of the guidelines that allow defining contents take place. Also at the micro-institutional level, we find the criteria used in learning assessment and certification, and in the outline and development of the reflection about teaching. The latter denotes the retrospective and prospective nature of teaching. The retrospective nature is connected with the historicity of classes and the possibility to recognize a past that is combined with a utopian view, which is typical of the political purpose of teaching. That is to say, bringing past into the present in order to think about the future.

However, the special characteristic of teaching in the school environment is that the teacher never thinks of teaching in terms of a single student; on the contrary, the challenge is to make teaching compatible with the whole group that constitutes the class. According to Souto (1993, p. 58) the group is a field of interconnections and meeting points where the individual, institutional and social aspects interweave, thus resulting in shared processes among subjects which have shared learning objectives.

\section{The Pedagogical and the Didactical in the Centre of Teaching}

How do we separate one from the other? What are the subtle differences? There are many ambiguities and confusion around pedagogy and didactics when analysing teaching practices (Morelli, 2016). The counterpart of both of them is the student. Didactics will deal with the multiple dialogues that the teacher suggests between the content and the student; intentionally causing the student to face new knowledge, and suggesting mental, practical, linguistic and social activities, among others, for the student to learn. Meanwhile, pedagogy will deal with the bond between the teacher and the student related with the process of culture transmission. That bond is affective, ethical, intercultural, transferable, asymmetric, emotional and historical. The teacher resorts to both pedagogy and didactics and presents them as relationships in teaching situations. A good way of representing teaching is through the didactic triad, which is the tripartite relationship between the teacher, the student and the subject matter, which is set in motion each time that something is taught. Although the relationship is generally established to try to explain the complexity of teaching, we should remember that there are as many didactic triads as students in the classroom, determining the characteristics of the relationship between the teacher and each student, and the relationship between the teacher and all of them as a group, simultaneously. With the help of Hudson (2016, p. 11), we explain the multiple and simultaneous relationships established in a didactic triad. This relationship, besides being conditioned by an institutional context, is deeply complex and is shaped by the special characteristics of each one of the members of the class and by the group as a class, simultaneously.

Let us take it one step at a time: what sets teaching in motion is the pedagogical relationship between the teacher and each student and between the teacher and the students collectively as a group. There is no teaching commencement which does not start by recognizing the characteristics that this bond acquires in each situation. But that pedagogical relationship is used by the teacher in order to methodologically intervene and to provoke, with a didactical intention, the moment in which the student is faced with content. This can occur during a lecture, during the statement of a problem, while reading a text, in the performance of an experiment, etc. This intention is influenced not only by culture but also by the classic technology used in teaching, such as the text, the blackboard, 
the guide, the laboratory, etc. and also by the digital technology in which the virtual environments create other teaching and learning conditions. The key task of the teacher is to guide, protect and channel the relationship between the student and the subject matter (Hudson, 2016). But the possibility of the teacher to establish an encounter between the student and a particular content masks another relationship such as the one between the teacher and the content, referred to above as subject matter content knowledge. What are the characteristics of this bond? This is an epistemological bond which is configured outside the teaching processes themselves. They account for the semantic fund that the teacher has been building since initial education and which the teacher continues to enrich and transform throughout the professional training and the subsequent experiences in teaching roles. This relationship provides the teacher with professional identity.

Below, we provide the didactic triad, produced by Hudson, with the multiple relationships that are established, including ICC in this configuration as a teaching issue.

\section{Figure 1. ICC and the Didactic Triad.}

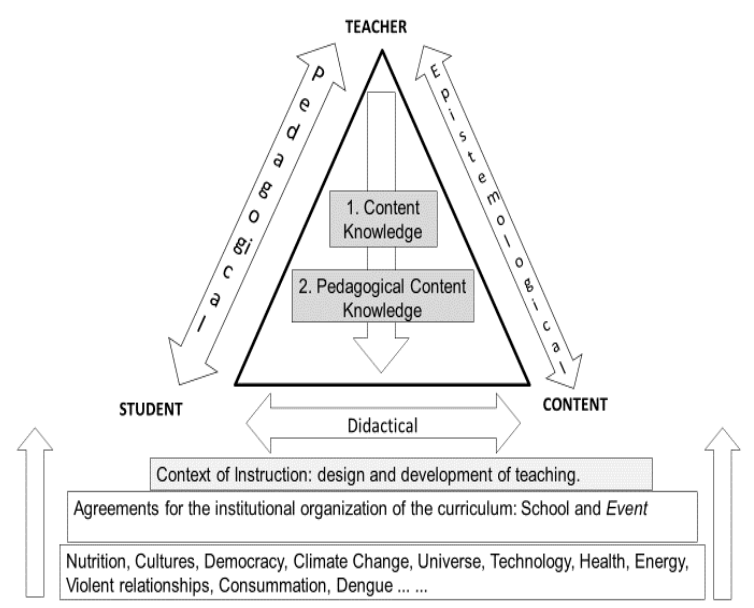

Source: Hudson, B. (2016, pp.4-7)

\section{Professional Artistry and Reflection}

The knowledge and abilities that the practitioners show in peculiar, conflictive and uncertain situations are part of what is called the professional artistry (Schön, 1992, 2013). In order to better describe the complexity and peculiarity to which this artistry refers to, the author presents three moments in which professional artistry is combined with reflection, and which in the case of teaching help with the professionalization towards teaching.

He calls the first moment the knowing-in-action and it is related to the tacit knowledge that a teacher possesses and uses almost without realizing of this knowledge. It is the competent execution and expertise shown while planning or developing a class, without being totally conscious, but still demonstrating knowledge of the subject matter. The author affirms that we tend to be unable to account for what we do or know, even when we know how to do it. In order to make knowing-inaction explicit and professionalize it, two reflective instances are added, which lend weight to considering teaching as an artistry because of the singularity and complexity involved. In this way, reflection-in-action appears as the moment in which action happens, the development of the knowing-in-action, where the teacher stops to think about what is going on, what he/she is doing and what he/she knows. Of course that, because of its complexity, the reflection is performed simultaneously, while the planning or development of teaching is in motion. Another moment, which is deeper and involves the improvement of teaching, is what the author calls reflecting-in-practice. As shown, this involves both tacit knowledge and simultaneous reflection, this time far from the moment of action, evoking the past. It is performed after the action has occurred and it allows for changes in the planning of future actions. According to Pérez Gómez (1992, pp. 419420) this reflection deals not only with the characteristics of the situation in which the action occurs, but also with the procedures used in diagnosis making, problems definition, goals setting, means election, and decision-making phases, where thinking schemes, implicit theories, beliefs and ways of representing reality are made explicit, known and analysed. This thought is established in connection with problematic situations and their context.

\section{The Methodological Task in Teaching}

Although it may seem obvious, we should ask ourselves: which is the role of methodology in teaching? And the answer we should provide is that it is the mandatory passage through which a subject matter/issue is transformed into content. The passage, justifies didactics in the teaching planning, arguing that the same subject matter/issue can be taught in different ways, depending on the methodology. However, without a methodological transformation process, there will be no possible content, whether in planning or development. This shows that content is a component of the teaching process, which leaves the subject matter/issue out of the process when transforming it. This way, we would not consider the subject matter/issue as a synonym of content; on the contrary, we need an epistemological and cognitive transformation which serves as a guide in the development of content, as a key moment in teaching. According to Shulman (2005), in the definition of methodology can be retrieved repertoires about methodological strategies that the teacher possesses when planning and practicing teaching. The methodology pretends, every time, to establish didactical relationships between the student and the content.

It is worth remembering the social and collective characteristics of the class and the challenge assumed when proposing methodologies for a group, knowing that each student has a particular relationship with knowledge. This means that the didactical relationship that the teacher establishes with the purpose of generating a dialogue between the student and the content should be multiplied by each one of the members of the group which constitute the class. However, according to Hudson (2016), what is important at the time of planning a class does not lie in the methodological aspect but in the decision made when selecting a subject matter. And we ask ourselves: is the election of a subject matter sufficient as regards teaching? It is not enough, it is 


\section{Camila Carlachiani et al / Curriculum, Teaching and Interdisciplinarity}

also necessary to include the methodological aspects in order to transform the subject matter/issue into content. All in all, the construction of content is a didactical process which cannot be disassociated in which the selection of a subject matter/issue and the methodological aspects take place. Thus, the question that becomes important is why that content and not another one should be taught. There are some arguments that state that the methodological is a process acquired, largely, through teaching experience and the constant reflection on teaching. Furthermore, authors like Schön (1992, 2013) and Shulman $(1986,2005)$ add that metacognition and professional reflection allow distinguishing a newly-graduated teacher from an expert one.

\section{The Relationship between Curricular Policies and Teaching}

We are aware of the importance of defining curricular policies for formal education. Without them, the teaching system lacks a key tool to solve the problem of the representation that the State has regarding citizen formation, the relevant knowledge and the role of school. A possible outline of curricular policies is defined taking centralization-decentralization as a starting point. The centralized systems are opposed to the decentralized systems and both of them are constructed in a disjunctive manner. It is one way or the other one and there is no possibility to combine or articulate both systems. A centralized system is defined from the top to the bottom, from the centre to the outside, where the national State defines the curricular policies so that they are reproduced in each of the country's classrooms. In order for this to happen, there should be regulation devices so that each agent undertakes to be the recipient of regulations, requirements, decrees, documents, etc. A system of curricular policies organized based on the spheres of curricular realization turns to be a useful technology for this model. The State, the Province, the institution and the classroom are a chained system which translates policies from one sphere to the other one moving down and outwards. This centralized model can be applicable because it is handled through the control and the self-control of each one of the subjects who are part of it in a hierarchical organization of tasks. On the opposite side, there is a decentralized system which allows the national realization sphere to define curricular policies regarding citizen formation, relevant knowledge and the role of school, but leaves what may happen in the intermediate organization of the curriculum unattended. However, the hopes are pinned in the school and classroom realization. While the centralized system is organized around control, the decentralized system is organized around trust. It is at this point where the opposition between the systems is established without reconciliation: if control is exercised it is because there is no trust and if there is trust then to control is needed. The centralized system requires self-controlled subjects while the decentralized system requires qualified subjects. The planning and development of teaching is the field of impact of these two models of curricular policies. Teaching is not a process which is isolated from the curricular policies; on the contrary, we understand that it is determined by them. Despite this, it is important to establish the challenge of resisting self-control and to generate other didactical conditions in order to organize the curriculum in the school and in the classroom, highlighting the teachers' autonomy, trust and training, as the subjects in charge of the didactic triad.

\section{The Interdisciplinary Core Content (ICC) and the Event}

Reflecting on teaching as a subject under dispute between the curriculum and the didactics fields, clarifying the complexities at stake in the didactic triad and analysing the teaching problem in the light of the missing paradigm (Shulman), lead to placing it at the centre of the educational scene. It is interesting to retrieve the central role of teaching and the teacher as the person in charge of that task, in the current political, economic, social and cultural contexts.

Educating the children and youth of the $21^{\text {st }}$ Century demands an opening towards a change of paradigm regarding the educational assumptions based on which the modern school educated hundreds of generations. This means that the universal truths, over which in the modern age the bases of the disciplines were built, fragmenting knowledge and granting the natural sciences a central position, are no longer applicable today. The student lacking knowledge, disciplined, in whom the teacher would deposit contents, no longer exists in the classrooms. On the other hand, the progress made in the fields of technology and the media make the society to live constantly connected, distances and timeframes to shorten, images to replace words and consumption to become a priority in people's lives, turning "having" more valuable than "being".

Today's world, which seems to have accelerated the movement and transformation rhythms, becomes difficult to grasp from the traditional categories and thinking schemes. We stay anchored to obsolete models and today's reality does not fit in. (Diana, 2010, p. 68).

We face the challenge of creating new methods of education which take into account the diversity of knowledge, that is to say, not only the science knowledge but also the knowledge that derives from experience, from culture and communities, from the different generations, from institutions, etc. where the narratives have equivalent legitimating criteria. In this regard, the possibility to accomplish multiple educational processes lie in accepting the different sets of languages and in recognizing the social issues assuming the commitment of translating them into academic knowledge so that they are taken into account in the curriculum development. It is useful to transfer to the educational scenarios what Lazzarato (2006, p. 44) understands when referring to an event.

The event shows what is intolerable in a period of time, but at the same time gives rise to new living possibilities. This new distribution of possibilities and desires opens, at its time, a process of experimentation and creation. The implications of the subjectivity mutations should be experienced and agencements, devices and institutions capable of displaying these new living possibilities should be created. 


\section{Camila Carlachiani et al / Curriculum, Teaching and Interdisciplinarity}

Likewise, thinking of education as an event allows for the developing of original content through creative and imaginative processes when facing complex situations. It is the acknowledgment of a particular social issue what, from the moment it is discussed at school, produces a change in the way it is understood. This author affirms that an event is not the solution of a problem, but the opening of possible problems which calls for creativity in order to offer an indefinite number of solutions beforehand. In line with this position, Badiou (2015, p. 202) offers a conceptualization of the evental sites, which is compatible with the one outlined by Lazzarato.

There are events uniquely in situations which present at least one site. The event is attached, in its very definition, to the place, to the point, in which the historicity of the situation is concentrated. Every event has a site which can be singularized in a historical situation (...) for there to be an event, there must be the local determination of a site.

An event is an outstanding social moment. We do not know exactly when it starts and this is not too important. What we do know is that through its recognition and by noticing its presence, it begins to be treated according to its problems, conflicts, peculiarities and the need to get to know it. One of the characteristics of an event is that, once that it has been noticed and treated, the social scenario is never the same. This means that the subjects take it as their own and from that moment onwards there is a change in the significance and the practices around it.

At the school level, referring to the event means taking as a starting point the treatment of a social issue typical of the context which emerges, causes commotion, moves, defying the institutional players to do something. In this way, it enables unthinkable approaching possibilities which require some creativity and collective work given that a sole knowledge area is not enough to manage its treatment. Badiou (2013, p.21) says that an event is the possibility to make something, which has been invisible and unthinkable, possible. But this event should be treated through a collective work. Thus, the interdisciplinary turns into an everyday occurrence at school, breaking the barriers and hierarchical organization built during the modern age among the different knowledge areas, while shaking the basis of school format. In this context, the school understood as a social institution built in a local context, is faced with several challenges in order to accomplish its mail goal: providing quality education which promotes the social inclusion of every child, adolescent and youngster. The teachers, who are jointly responsible of education as an act of public policy, should assume this task after a change in the paradigm.

\section{The School and the Curriculum}

In Argentina, in accordance with the National Education Act (Ley de Educación Nacional, LEN) number 26.206/06, the purposes of the primary school education are related with guaranteeing a comprehensive education which allows the access to a set of common knowledge, providing equal opportunities regarding the learning of meaningful knowledge, generating pedagogical conditions for the use of information and communications technology, promoting the training in ethical and citizenship values, encouraging the autonomous work and the habits of solidarity and cooperation in coexistence, offering the knowledge and the cognitive strategies to continue with the secondary education, giving opportunities for a comprehensive physical training considering the game as a necessary activity towards cognitive development. Likewise, the secondary education has three main purposes: citizenship training, access to the working world and continuity to higher education.

In the meso-level, in Santa Fe Province all of the above implies working on the basis of three pillars in which the education policy is supported: socio-educational inclusion, quality education and school as a social institution. Thinking about the school based on these guidelines means understanding it as an open and flexible institution which drives human development and contributes to democratic life and coexistence. At the same time, the school as a social institution cooperates by making visible problems that arise in macro and micro-cultural dimensions.

Quality education is a collective construction of knowledge which relevance and appropriateness are meaningful in the lives of the students. Educating with quality is a responsibility of the adult generation, which assumes the commitment of providing the cultural legacy as a public asset, with the intention of guaranteeing equality in the distribution of cultural and symbolic resources. In this respect, quality education is essential to overcome fragmentation and social inequality. It implies working collaboratively towards socioeducative inclusion. One does not exist without the other one. Guaranteeing quality education means making sure that everybody stays at school and learns.

Meanwhile, socio-educational inclusion refers to the creation of quality access, retention, learning, graduation and exit conditions for every student in the Santa Fe educational system. The core values in which inclusion is based are solidarity and emancipation. The first one is understood as something which generates movement related with the satisfaction of the needs of subjects whom rights have been violated; whilst the second one is the horizon to achieve, centred in an autonomous subject fully capable of deciding in accordance with their citizenship condition. Likewise, it is thought that for education practices based in solidarity and emancipation to exist, it is necessary to review the historical mandates across the education system, which obstruct the right to get an education.

The quality education and the socio-educational inclusion are two pillars in which the school as a social institution is based. This implies thinking of it in a broad sense, from a specific context that generates movement because of its particular problems. The school is opened to the community and works with other organizations and players in the civil society in an articulated manner through inter-institutional networks.

This way, the curriculum as an institutional development unit, becomes an essential tool in order to work based on these three pillars. The committed action of teachers is important, 
then, so that the curriculum is not a dead letter but develops, bringing school to life. In this respect, Zabalza (2000) talks about three very important issues at the time of developing a curriculum: (a) understanding the curriculum as a comprehensive education process, (b) the school institution as an education unit with its own identity and (c) the teacher as a curriculum professional.

From this perspective, our proposal is teaching through ICC, framed in institutional curricular projects, in which the subjects are based in natural sciences and social sciences. These are configured inside the institutions as a way of approaching teaching. It is not a parallel project to the development of the classes. They do not entail sporadically dealing with social issues. They do not mean "something extra" to add to school issues.

What they are intended for is extremely deeper. They are about shaking the heart of education practice, rethinking and redeveloping the school teaching and learning methods. This also implies the possibility to enable new ways of being, participating, moving and dwelling in school, to break some barriers regarding space/time dimensions as well as the boundaries between disciplines and the hierarchical organization of knowledge.

Teaching form the perspective of ICC necessarily requires willingness towards team working by supervisors, headship and teachers. Generating the time and the places necessary to meet, discuss, reflect and plan collectively is the first step towards working in this direction.

Teaching, as a political and ethical act, demands that teachers, in their role as State agents, guarantee the right to learn and educate themselves that students have, and also transmit the knowledge understood as a public asset contributing with its democratization. This means that the teaching practices, materialized through different methods, proposals and activities, cannot be thought or planned detached from this conception. Because of that, teaching is a social action that takes into account the singularities of each subject, respecting the learning times and enlarging the possibilities to promote and appropriate the socially meaningful knowledge. In this respect, the access to teaching resources that come from different languages favours the openness towards experiencing learning from different places and senses.

The teaching task is necessarily a collective one. It is in the encounter with other colleagues where the disciplinary formation is enriched, opening new fields of thought. This does not mean pushing into the background or abandoning its own specific characteristics but opening the possibility to work as a team through exchanges with people from other disciplinary fields in order to address the complexity of the social issues which, understood as an event, are the starting point in the teaching of ICC. We understand these as knowledge that should be taught from an interdisciplinary perspective built on school disciplines such as History, Ethics, Economics, Geography, Philosophy, Physics, Mathematics, Chemistry, Biology, Psychology, Political Sciences. The configuration of ICC is based on social and cultural problems that are specific of the context in which the students live.
It is about creating teaching proposals that work based on an integrated understanding of knowledge, leaving behind fragmented and patchy visions. Some interdisciplinary cores can derive from the following issues/problems: Climate change, globalization, energy, environmental education, democracy, social welfare, violent relationships, human condition, life, communication, consumption, art, technology, cultures, sciences, eating habits, health care.

Figure 2: Interdisciplinary Core Content: the education in events.

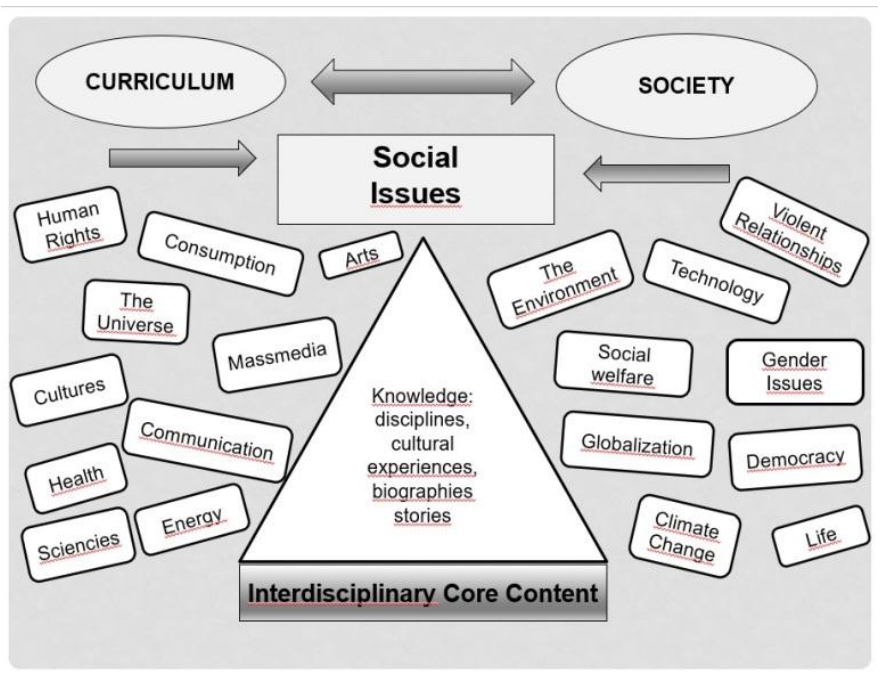

Source: Carlachiani, C. (2016, p. 28)

The main purpose of teaching ICC is to foster and promote a comprehensive education that allows creating bonds between the students and their context so that they can grasp the world through the interdisciplinary construction of knowledge. This means enabling teaching and learning environments which leave behind fragmented and patchy visions of contents, identifying the school institution as a unit of curricular definition and development. At the same time, it is important to promote the use of educational technologies as tools which generate an impact over the school practices contributing towards the collective and cooperative construction between generations. Lastly, it is very important to create opportunities for dialogue and participation which allow the construction of coexistence through the implementation of values in the socialization process.

In this framework, the teachers plan and develop, through institutional work teams, teaching proposals which deal with the configuration of ICC. It is necessary to generate learning environments in which the students play an active role which allows them to live true learning experiences. This way, the school recreates the curriculum based on the institutional criteria in order to arrange teaching in a sequence. To achieve this, the institutional culture will focus in the following aspects:

[1] The collaborative professionalism of the teacher.

[2] The leadership of the headship regarding guidance and assistance provided to teachers.

[3] The proper pedagogical perspective as regards interdisciplinary work. 


\section{Camila Carlachiani et al / Curriculum, Teaching and Interdisciplinarity}

[4] The collective construction of knowledge.

[5] Technological perspectives in education.

[6] Willingness to intervene in physical environments.

\section{Curricular Development}

As it was previously stated, the curriculum implementation task requires the mutual collaboration of teachers and headship, recognizing students as social subjects without forgetting parents, families and the education community. One way of carrying out this task is through the execution of institutional projects which deal with the teaching and the learning of ICC. This means selecting and organizing school content from a perspective which overcomes disciplinary fragmentation. This allows using as starting point the regional issues which generate inventive attitudes of the students; promotes scientific and technological literacy in the educational environment; fosters collaboration attitudes among all the institutional players; improves science teaching, generates meeting points, debates and meaning construction; awakens critical spirit and curiosity, allows the social appropriation of sciences, arts and technology contributing to a comprehensive education of students; improves their communication skills through the exchange of educational experiences and bring school closer to community.

What is important in this type of approach is that the students have an interdisciplinary view of knowledge and at the same time are able to intervene in their own communities. It is recommended to identify ICC with issues that reflect specific content of the curricular areas. In the words of Cullen (1997, p. 110), "at school, the interdiscipline shows three different logics: the one from science, the one from the curriculum and the one from the school institution", although articulating their relative autonomy is not an easy task. We should start from an holistic point of view, from issues found in the social and cultural world of the school groups, in order to collectively formulate questions, working hypothesis and possible answers which promote the development of creativity and imagination focusing on the "doing" and the "knowing". Working from this perspective implies understanding that "the interdisciplinarity is essentially a process and a working philosophy which is set in motion when facing problems and issues that rise concern in each society" (Torres Santomé, 1994, p. 67).

\section{Content Organization}

The issue regarding "what" to teach has been historically the centre of the pedagogical scenario since the bond between teacher and students is based on it. In this proposal, ICC is the link which boosts the development of teaching and learning. According to Gentiletti (2012, p. 61):

The sciences, philosophy and arts have a shared purpose which is to broaden and increase the complexity of everyday knowledge. All these varieties of human creation build knowledge which goes beyond the restrictions set by the current socio-cultural conditions, offering new points of view. It is interesting then to focus on the "how". How to teach school contents that become socially meaningful learning in the lives of the students. As we have been explaining, the proposal is to take as starting points the regional issues typical of the context in which the student live which lead to dealing with school contents derived from the curricular areas that are part of the institutional education proposal. From each curricular area, the disciplines contribute to deal with the social issues thus constituting ICC and enabling the debate, the exchange and the construction of meaning, which enables students to come up with creative and innovative answers. Thinking about these issues as events, opens the possibility of developing new, original content and dealing with emerging social issues which generate the opportunity to create socially meaningful learning.

As Orozco Fuentes (2006, p. 25) states:

The socially meaningful learning (aprendizajes socialmente significativos, ASS) incorporate knowledge produced through experience, includes the unlearned knowledge which is meaningful in people's lives and cultural identities. The ASS articulate school practices with community, social, cultural and productive practices (...); learning interaction does not only occur inside the school but also between the school and the community. This is a way of didactical expression of the bond between curriculum and society.

In this working dynamic it is essential the participation, through guidance and assistance, of the teachers involved, generating learning environments. In this way, Siede (2013, p. 170) affirms that each one of the students participates in a dialogue based on arguments and counterpoints while the teacher is responsible for guaranteeing equal conditions in the dialogues and promoting the further analysis. In order to do that, it is necessary that the teachers possess a deep knowledge of the discipline they teach and create teaching strategies which foster true learning experiences without losing sight of the impact that education technology can cause on them. What is interesting about this approach is the possibility to generate new knowledge based on the intersection of the three dimensions involved: disciplinary, technological and pedagogical (Shulman, 1986). However, it is important not to lose sight of the ethical and political role of the teachers because their task is deeply linked to the transmission and recreation of culture so their position cannot be neutral.

It is about offering a cultural legacy so that they can make something new out of it. It is about offering opportunities to think along with others based on specific situations and with all the tools offered by the cultural legacy that we inherited, but also being opened to the uncertainties of a future which will bring new challenges. It is about placing political action at the centre of the scene in order to interpret it based on ethical, legal and political categories. (Siede, 2013, p. 174).

\section{Acknowledgements}

To Ian Westbury, Professor Emeritus at the University of Illinois at Urbana-Champaign, for connecting us with the world of teaching.

To Claudia Balagué, Minister of Education of Santa Fe, who translated this into a possible project.

To Oscar Di Paolo, Secretary of Education of Santa Fe, for the 
trust.

\section{References}

[1] Badiou, A. (2015). El ser y el acontecimiento. Buenos Aires: Manantial.

[2] Bolivar, A. (2005). Conocimiento didáctico del contenido y didácticas específicas. Profesorado. Revista de currículum y formación del profesorado, 9, 2 (2005). DOI: http://www.ugr.es/local/recfpro/Rev92ART6.pdf.

[3] Carlachiani, C. (2016). Los Núcleos Interdisciplinarios de Contenido y el acontecimiento. In Morelli, S. (Coordinadora). Núcleos Interdisciplinarios de Contenidos NIC. La educación en acontecimientos. Rosario: Homo Sapiens Ediciones.

[4] Cullen, C. (1997). Crítica de la razones de educar. Temas de filosofía de educación. Buenos Aires: Paidós.

[5] Diana, C. (2010). Pensar lo interdisciplinario en la escuela secundaria. Revista Novedades Educativas. Año 22. N²34. Junio de 2010. Buenos Aires.

[6] Diker, G. (2012). Cómo se establece lo común. In Diker y Frigerio (comps). Educar posiciones acerca de lo común. Serie Seminarios del CEM.

[7] Gentiletti, M. G. (2012). Construcción colaborativa de conocimientos integrados. Buenos Aires: Noveduc.

[8] Hudson, B. (2016). Didactics. En Wyse, D., Hayward, L. \& Pandya, J. The SAGE Handbook of Curriculum, Pedagogy and Assessment: Two Volume Set. London: SAGE Publications Ltd. DOI:

[9] http://dx.doi.org/10.4135/9781473921405.n7

[10]Lazzarato, M. (2006). Políticas del acontecimiento. Buenos Aires: Tinta y Limón.

[11]Morelli, S. (Coordinadora) (2016). Núcleos Interdisciplinarios de Contenidos NIC. La educación en acontecimientos. Rosario: Homo Sapiens Ediciones.

[12] Orozco Fuentes, B. (2006). Aprendizajes socialmente significativos: en diálogo y tensión con los discursos del aprendizaje y las competencias en educación. Unpublished.

[13] Pérez Gómez, A. (1993). La función y la formación del profesor/a en la enseñanza para la comprensión. Diferentes perspectivas. In Gimeno Sacristán, J. y Pérez Gómez, A. Comprender y transformar la enseñanza. Madrid: Morata.

[14] Pinar, W. (2009). Bildung and the Internationalization of Curriculum Studies. In Ropo, E. and Autio, T. (eds). International Conversations on Curriculum Studies, 2341. Rotterdam: Sense Publishers.

[15] Pinar, W. (2012). What is Curriculum Theory. New York: Routledge.

[16] Schön, D. (1992). La formación de profesionales reflexivos. Barcelona: Paidós.

[17] Schön, D. (2013). The Reflective Practitioner. How Professionals Think in Action. Farnham: Ashgate.

[18] Shulman, L. (1986). Those Who Understand: Knowledge Growth in Teaching. Educational Researcher, Vol. 15, No. 2. (Feb., 1986), pp. 4-14. http://links.jstor.org/sici?sici=0013-
$189 X \% 28198602 \% 2915 \% 3$ A2\%3C4\%3ATWUKGI\%3 E2.0.CO\%3B2-X

[19] Shulman, L. (2005). Conocimiento y enseñanza: fundamentos de la nueva reforma. Profesorado. Revista de currículum y formación del profesorado, 9, 2 (2005). DOI: http://www.ugr.es/local/recfpro/Rev92ART1

[20] Siede, I. (2013). La educación política. Ensayos sobre ética y ciudadanía en la escuela. Buenos Aires: Paidós.

[21] Souto, M. (1993). Hacia una didáctica de lo grupal. Buenos Aires: Miño y Dávila Editores.

[22] Torres Santomé, J. (1994). Globalización e interdisciplinariedad: el currículum integrado. Madrid: Morata.

[23]Zabalza, M. A. (2000). Diseño y desarrollo curricular. Madrid: Narcea. 